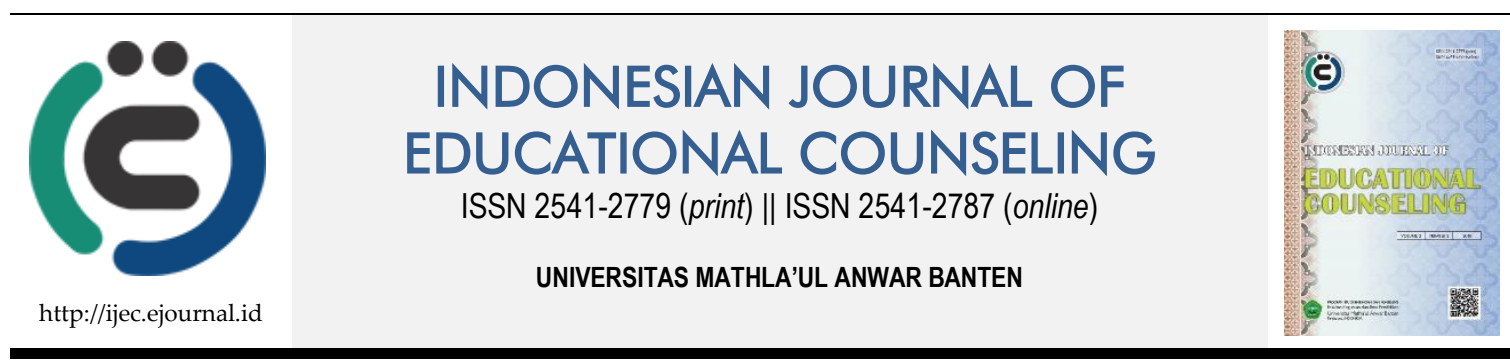

Theoretical/Conceptual Article

\title{
Analisis Strategi Regulasi Emosi Cognitive Reappraisal untuk Menurunkan Perilaku Cyberbullying
}

\author{
Ratna Wulandari ${ }^{1}$, Nur Hidayah ${ }^{2}$ \\ 1, 2 Universitas Negeri Malang
}

\begin{tabular}{|c|c|}
\hline ARTICLE INFO & ABSTRACT \\
\hline $\begin{array}{l}\text { Article History: } \\
\text { Received 12.12.2017 } \\
\text { Received in revised } \\
\text { form 22.05.2018 } \\
\text { Accepted 30.06.2018 } \\
\text { Available online } \\
\text { 22.07.2018 }\end{array}$ & $\begin{array}{l}\text { Cyberbullying is a behavior of intimidating, mocking, humiliating or disturbing } \\
\text { others, either individually or in groups conducted in cyberspace such as social } \\
\text { media such as facebook, instagram, twitter, BBM, and whatsapp. To be able to } \\
\text { reduce the tendency of cyberbullying behavior can be done by way of emotional } \\
\text { regulation using cognitive reappraisal strategy, because it is known that the } \\
\text { emotional condition can affect individual behavior. Emotional regulation is a } \\
\text { process in which individuals influence, control, and adapt their emotions, when } \\
\text { they have them, and how they feel and express these emotions at the right level } \\
\text { of intensity to achieve a goal. Emotion regulation strategy that can be used one } \\
\text { of them is cognitive reappraisal emotional regulation strategy. The purpose of } \\
\text { this theory is to examine the application of cognitive reappraisal emotional } \\
\text { regulation strategy to decrease the tendency of cyberbullying behavior of } \\
\text { students. }\end{array}$ \\
\hline & Keywords: Cognitive Reappraisal, Cyberbullying; Emotion Regulation. \\
\hline
\end{tabular}

DOI: $10.30653 / 001.201822 .27$

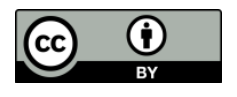

This is an open access article distributed under the terms of the Creative Commons Attribution 4.0 International License, which permits unrestricted use, distribution, and reproduction in any medium, provided the original work is properly cited. ○ 2018 Ratna Wulandari, Nur Hidayah.

\section{PENDAHULUAN}

Masyarakat di era sekarang tidak bisa lepas dari media sosial. Hampir seluruh orang di dunia ini memiliki sosial media, tidak hanya satu atau dua, bahkan mereka memiliki tiga atau lebih sosial media seperti facebook, instragram, path, whatsapp, twiter, youtube, BBM, dan masih banyak lagi. Begitupun penggunaan media sosial di kalangan remaja pada saat ini juga merupakan sesuatu yang tidak dapat dihindari lagi. Hampir setiap hari remaja mengakses media sosial hanya untuk sekedar mencari informasi ataupun melihat postingan orang lain. Namun dengan munculnya media sosial (Medsos) di kalangan remaja juga membawa dampak negatif. Salah satu dampak negatifnya adalah munculnya fenomena bullying di dunia maya. Para pengguna sosial media dapat dengan mudah mengomentari status yang dibuat oleh pengguna lain, baik dengan komentar yang positif ataupun negatif. Pengguna juga dapat dengan mudah menuliskan status yang berisi kata-

${ }^{1}$ Corresponding author’s address: Universitas Negeri Malang. Email: ratnawulan54@yahoo.com. 
kata kasar, vulgar, atau rasisme, atau bahkan mengancam atau memfitnah orang lain melalui akun jejaring sosial yang dimiliki. Bullying yang terjadi di dunia maya atau cyber dijuluki dengan cyberbullying. Cyberbullying sama dengan bullying yang terjadi pada umumnya, yaitu sama-sama mengintimidasi ataupun mengganggu orang yang lemah, cyberbullying ini pada umumnya banyak terjadi di media sosial.

Perbedaan antara cyberbullying dengan bullying adalah tempat di mana seorang pembully atau mobbing (julukan untuk satu kelompok pem-bully) melakukan intimidasi, ancaman, pelecehan, dan lain-lain terhadap target. Cyberbullying adalah kejadian ketika seorang anak atau remaja diejek, dihina, diintimidasi, atau dipermalukan oleh anak atau remaja lain melalui media internet, teknologi digital atau telepon seluler.

Hasil dari penelitian yang dilakukan oleh Hinduja dan Patchin (2012) mengungkapkan fakta bahwa terdapat pertumbuhan tingkat bunuh diri pada anak dan remaja usia 10 sampai 19 tahun pada tahun-tahun terakhir. Kemudian dalam harianriau.co (2017) disebutkan beberapa kasus cyberbullying yang cukup menggemparkan dunia, yaitu seperti di Amerika tahun 2014 seorang remaja yang menembak dirinya sendiri karena tidak tahan dengan perilaku bully yang dilakukan teman-temannya kepadanya. Selain itu Kompas.com juga memberitakan bahwa instagram menjadi media sosial yang paling umum untuk digunakan melakukan perundungan (bully) di internet atau cyberbullying. Tidak kurang dari 10.000 remaja berusia 12 hingga 20 tahun di Inggris dijadikan sebagai sumber survei. Hasilnya menunjukkan, lebih dari 42 persen korban cyberbullying mengaku mendapatkannya di Instagram, sebagaimana dilaporkan Mashable dan dihimpun KompasTekno, Jumat (21/7/2017). 37 persen korban cyberbullying mengaku mengalami perundungan via Facebook dan 31 persen di Snapchat. Sementara itu Liputan6.com (2013) juga menuliskan bahwa Beberapa korban cyberbullying bahkan sampai bunuh diri akibat tekanan yang diterimanya melalui internet. Seperti seperti kejadian pada tanggal 26 Mei 2018, seorang pemuda di Yogyakarta yang melakukan tindakan nekat dengan menabrakkan dirinya ke kereta api, perbuatan tersebut diduga karena tekanan dan hujatan di Medsos akibat kegagalan dalam menyelenggarakan acara musik, dimana dia yang menjadi event organizer (EO)-nya. Selain itu masih ada 6 orang lagi yang dikabarkan bunuh diri akibat tidak tahan dengan bully-an yang mereka terima di dunia maya.

Melihat dampak dari cyberbullying yang sangat mengerikan di atas, maka diperlukan cara untuk mengurangi dan mencegak dampak bullying tersebut salah satunya dengan mengatur atau meregulasi emosi yang kemudian akan berdampak pada perilaku. Regulasi emosi merupakan proses di mana individu mempengaruhi emosi yang mereka miliki, kapan mereka memilikinya, dan bagaimana mereka merasakan dan mengekspresikan emosi ini (Gross, 1998). Menurut Pratisti (2013) Strategi regulasi emosi yang tidak tepat akan berdampak negatif, sedangkan strategi regulasi emosi yang tepat akan berdampak positif. Sementara Mujiono (2015) menemukan bahwa kemampuan pengelolaan emosi berhubungan dengan perilaku bullying siswa. Jadi jika pengelolaan emosi individu baik, maka tidak akan terjadi perilaku bullying, begitu juga sebaliknya jika perilaku bullying siswa tinggi kemungkinan kemampuan pengelolaan emosi siswa kurang baik. Puspitasari dalam penelitiannya menunjukkan bahwa ada hubungan negatif yang sangat signifikan antara regulasi emosi dengan kecenderungan perilaku bullying. Regulasi emosi berfungsi untuk menghentikan dan mengatur emosi yang muncul baik itu secara otomatis maupun spontan (tidak sadar) sebelum melakukan aksi dalam peristiwa tertentu. Jika regulasi emosi individu baik, maka individu tersebut juga akan dapat mengontrol perilakunya, termasuk perilaku cyberbullying. 
Strategi regulasi emosi setiap orang dapat berbeda-beda. Gross menyebutan ada dua strategi regulasi emosi yang dapat digunakan, yaitu strategi cognitive reappraisal dan strategi expressive suppression. Dari hasil penelitian Gross \& John (2003) diketahui bahwa individu yang menggunakan kemampuan regulasi emosi dengan strategi cognitive reappraisal dapat lebih puas dengan kehidupannya, lebih optimis, dan memiliki harga diri yang baik dan mengalami lebih sedikit gejala depresi, sehingga ia memiliki kesejahteraan psikologis. Sedangkan individu yang menggunakan strategi regulasi emosi expressive suppression dalam kehidupan sehari-harinya, maka akan cenderung merasa tidak menjadi diri sendiri karena dalam menghadapi situasi yang menekan/stres, ia akan lebih memilih untuk menutupi perasaan batin mereka (menampilkan respon emosi yang berbeda dengan yang sesungguhnya individu rasakan), sehingga kurang berhasil dalam memperbaiki suasana hati dan emosi. Individu yang kurang dalam berinteraksi dengan orang lain dan berbagi masalah dengan orang lain cenderung mempunyai kesejahteraan psikologis (wellness) dan harga diri yang rendah, kurang puas dengan kehidupan dan memiliki gejala depresi yang lebih tinggi. Oleh karena itu, upaya kajian mengenai strategi regulasi emosi cognitive reappraisal untuk menurunkan kecenderungan perilaku cyberbullying pada siswa/remaja penting mendapat perhatian.

\section{KAJIAN LITERATUR}

\section{Cyberbullying}

Peter Smith et al (2008) mendefinisikan cyberbullying sebagai perilaku agresif yang disengaja dan dilakukan secara individual maupun berkelompok dengan menggunakan media komunikasi elektronik. Perilaku tersebut dilakukan secara berulang dan dari waktu ke waktu terhadap korbannya. Hal yang serupa juga diungkapkan oleh Feinberg dan Robey (2009), cyberbullying meliputi pengiriman teks atau gambar yang berbahaya dan kejam dengan menggunakan internet (misalnya, instant messaging, e-mail, chatting, dan situs jejaring sosial) atau perangkat komunikasi digital lainnya, seperti ponsel. Tidak seperti bullying, para pelaku cyberbullying tidak selalu memiliki tampilan fisik yang kuat dan besar dan biasanya tidak diketahui identitasnya (Kiriakidis \& Kavoura, 2010). Perilaku cyberbullying adalah perilaku mengirimkan atau melakukan postingan dengan materi yang menyakitkan dan mengganggu kepada dan/ tentang orang lain. Perilaku ini dilakukan secara berulang dan disengaja melalui perantara internet dan teknologi digital lain, seperti melalui e-mail, aplikasi pesan instan (instan messaging), akun jejaring sosial, chat rooms, dan pesan digital atau gambar yang dikirimkan melalui komputer, telepon selular, atau alat komunikasi lainnya.

\section{Regulasi Emosi}

Bentuk emosi yang muncul pada remaja antara lain rasa marah, malu, takut, cemas, cemburu, iri hati, sedih, gembira, kasih sayang, dan ingin tahu (Nisfiannoor \& Kartika, 2004). Emosi positif muncul ketika individu dapat mencapai tujuan sedangkan emosi negatif muncul ketika mendapatkan halangan saat ingin mencapai tujuan tersebut (Salamah, 2012). Thompson (1994) mengatakan bahwa regulasi emosi dapat dilihat sebagai proses awal yaitu merasakan, memelihara, dan mengelola emosi untuk mencapai tujuan dan memudahkan dalam upaya menyesuaikan diri dengan fungsi sosial. Eisenberg mengartikan regulasi emosi sebagai proses awal, memelihara, mengatur perasaan yang berkaitan dengan fisiologis. Gross (2014) mengatakan bahwa regulasi emosi adalah kemampuan seorang dalam mengelola emosi dalam rangka mencapai keseimbangan emosional sehingga mampu mengungkapkan emosi yang tepat. Regulasi emosi juga 
merupakan kemampuan untuk tetap tenang saat berada di bawah tekanan (Rasyid, 2012). Regulasi emosi juga diasumsikan sebagai faktor penentu keberhasilan seorang individu dalam usahanya untuk berfungsi secara normal seperti proses beradaptasi dan dapat memberi respon yang sesuai (Thompson, 1994). Berdasarkan pengertian-pengertian tersebut, dapat dikatakan bahwa regulasi emosi merupakan kemampuan dan proses seseorang untuk merasakan, memelihara, dan mengelola emosi agar dapat memberikan respon yang tepat.

Terdapat lima tahapan dalam proses regulasi emosi, yaitu pemilihan situasi (situation selection), perubahan situasi (situation modification), penyebaran perhatian (attentional deployment), perubahan kognitif (cognitive change), dan perubahan respon (response modification) (Gross, 2014; Gross \& Jazaieri, 2014). Berikut penjelasan lima tahapan tersebut.

1) Pemilihan situasi (situation selection) meliputi tindakan menghindari atau mendekati objek dan situasi tertentu dalam upaya mengurangi atau meningkatkan emosi. Situation selection dapat dilakukan oleh diri sendiri maupun oleh orang lain.

2) Perubahan situasi (situation modification) adalah usaha mengubah situasi secara langsung untuk mengalihkan emosi yang dirasakan. Terkadang sulit untuk membedakan antara situation selection dan situation modification. Akan tetapi, situation modification lebih menekankan pada perubahan lingkungan fisik, seperti memberikan prihatin kepada teman yang sedang memiliki masalah.

3) Penyebaran perhatian (attentional deployment) merupakan bentuk pengelolaan emosi dengan mengalihkan perhatian yang tidak menggunakan fungsi alat indera, pengubahan arah perhatian yang dapat dilakukan dengan distraksi atau konsentrasi, dan merespon kembali emosi tersebut. a) Distraksi merupakan memfokuskan perhatian pada aspek yang berbeda dari sebuah situasi atau memindahkan perhatian dari sebuah situasi yang dapat menimbulkan emosi ke situasi yang tidak menimbulkan emosi. b) Konsentrasi adalah memfokuskan perhatian kepada situasi yang menimbulkan emosi. Seorang yang mengarahkan perhatian secara berulang kepada perasaan yang dialami dan konsekuensinya dikenal dengan istilah perenungan. Perasaan tidak tenang atau resah akan meningkat apabila perhatian difokuskan pada ancaman-ancaman di masa yang akan datang. Namun, memfokuskan perhatian pada ancaman di masa yang akan datang cenderung dapat menurunkan respon emosi yang negatif.

4) Perubahan kognitif (cognitive change) yaitu menghubungkan dan membandingkan situasi yang dialami dengan situasi yang berada di bawah situasi yang dialami tersebut.

5) Perubahan respon (response modulation) terjadi pada bagian akhir yang merupakan respon seseorang setelah mengalami emosi. Respon tersebut dapat dilakukan pada aspek fisiologis, seperti penggunaan obat dan relaksasi.

Menurut Thompson (1994) proses emosi dipengaruhi oleh kesadaran, pemahaman, dan jenis kelamin. Di sisi lain, proses regulasi emosi juga dipengaruhi oleh hubungan antara orang tua dan anak, umur dan jenis kelamin, serta hubungan interpersonal. Perasaan yang ada diantara keluarga dapat bersifat positif dan negatif. Perasaan positif dalam keluarga dapat berupa kehangatan, sensitivitas, kasih, cinta. Sebaliknya, perasaan negatif dapat berupa penolakan yang berujung pada permusuhan (Rice, 1999). Adanya kebutuhan perasaan seperti di atas, menunjukkan bahwa orang tua memiliki pengaruh 
pada emosi anaknya (Nisfiannoor \& Kartika, 2004). Selain itu, umur dan jenis kelamin juga mempengaruhi regulasi emosi seseorang. Salovey dan Sluyter (1997) menyebut bahwa perempuan dengan rentang usia 7 sampai dengan 17 tahun cenderung dapat melupakan emosi dari peristiwa yang menyakitkan dibandingkan dengan laki-laki. Hubungan interpersonal dan individual juga memiliki pengaruh pada regulasi emosi karena saling berhubungan satu dengan yang lain dalam hal perkembangan regulasi (Mayer \& Salovey, 1997). Berdasarkan pembahasan tersebut, dapat disimpulkan bahwa hubungan antara orang tua dan anak, umur dan jenis kelamin, serta hubungan interpersonal mempengaruhi seorang individu mengelola atau meregulasi emosi.

\section{Strategi Cognitive Reappraisal}

Strategi regulasi emosi menurut Gross dan Thompson (1997) yaitu cognitive reappraisal (antecendent focused) dan expressive suppression (responsefocused). Antecendence focused emotion regulation atau reappraisal, yaitu berpikir tentang situasi untuk menurunkan dampak emosional sedangkan response focused emotion regulation atau suppresion menghambat keluarnya tanda-tanda emosi. Selain itu, terdapat beberapa bentuk strategi regulasi emosi yang dikemukakan oleh Garnefski, Kraaij, \& Spinhoven (2001), yaitu cognitive reappraisal merupakan bentuk perubahan kognitif yang melibatkan penafsiran terhadap situasi yang secara potensial akan memunculkan emosi melalui suatu cara yang mampu merubah pengaruh emosinya bentuk ini merupakan antecedent-focused strategy yang terjadi pada saat awal sebelum kecenderungan respon emosi terbangkitkan secara penuh. Hal ini berarti bahwa cognitive reappraisal dapat merubah seluruh lintasan emosi dan berikutnya secara efisien. Lebih khusus lagi, ketika digunakan untuk meregulasi penurunan emosi negatif, reappraisal akan mengurangi komponen emosi yang negatif, baik secara perilaku maupun pengalaman.

\section{DISKUSI}

Perilaku cyberbullying saat ini sudah menjadi fenomena yang sangat memprihatinkan. Dampak yang ditimbulkannya sangat beragam mulai dari rendahnya rasa percaya diri sampai dampak yang paling mengerikan yaitu bunuh diri. Dari hasil kajian teori berkaitan dengan perilaku cyberbullying yaitu perilaku yang meliputi pengiriman teks atau gambar yang berbahaya dan kejam dengan menggunakan internet (misalnya, instant messaging, e-mail, chatting, dan situs jejaring sosial) atau perangkat komunikasi digital lainnya, seperti ponsel. Kowalski et al (2012) mengemukakan berbagai bentuk perilaku yang dikategorikan sebagai cyberbullying, yaitu: a) Flaming: perdebatan, diskusi secara online melalui pesan elektronik yang menggunakan bahasa vulgar dan ofensif. b) Harasment/Pelecehan: pengulangan pengiriman pesan ofensif, tidak menyenangkan dan menghina. c) Denigration/Pencemaran nama baik: untuk menghina atau mencemarkan nama baik seseorang secara online untuk mengirim rumor, gosip atau kebohongan, biasanya ofensif dan kejam, untuk merusak citra atau reputasi seseorang atau hubungannya dengan orang lain. d) Impersonation/Peniruan: mendapatkan informasi pribadi atau penampilan seseorang (nick, password, dll), dengan tujuan untuk menyamar sebagai orang lain dan membuat orang itu terlihat buruk, melakukan tindakan tidak pantas, merusak reputasinya atau untuk merusak hubungannya dengan orang lain. e) Exclusion: Mengucilkan seseorang dalam sebuah grup online atau forum diskusi online secara disengaja. f) Outing dan Trickering: untuk menyebarkan rahasia seseorang, informasi atau foto secara online. g) Cyberstalking: pengiriman pesan berulang yang menyertakan ancaman atau sangat mengintimidasi. 
Hampir semua remaja yang masih duduk di bangsu sekolah mempunyai media sosial seperti facebook, instagram, twitter, whatsapp, path, dan lain-lain. hal ini membuat remaja menjadi sasaran utama perilaku cyberbullying. Seperti yang telah dipaparkan di atas diketahui bahwa instagram menjadi media sosial yang paling umum untuk digunakan melakukan perundungan (bully) di internet atau biasa disebut sebagai cyberbullying. Oleh sebab itu sangat penting untuk mencari cara yang bisa dilakukan oleh tenaga pendidik terutama konselor di sekolah agar peristiwa cyberbullying dapat dicegah sedini mungkin.

Berdasarkan hasil kajian teori berkaitan dengan perilaku cyberbullying dan strategi regulasi emosi cognitive reappraisal diketahui bahwa sebenarnya kemampuan individu dalam meregulasi emosi berbeda-beda, strategi yang digunakan juga berbeda. Keterampilan meregulasi emosi dapat dipelajari dan dilatih. Kondisi emosional seseorang dapat berpengaruh terhadap perilakunya sehari-hari sebagai sebuah bentuk respon emosional terhadap kondisi atau keadaan yang kemudian dinilai dengan tujuan aktif individu. Berdasarkan penelitian sebelumnya juga dapat diketahui bahwa ternyata ada hubungan signifikan antara kemampuan regulasi emosi individu dengan kecenderungan perilaku bullying.

Cognitive reappraisal memberikan cara efektif untuk mengatur emosi dengan merubah perhatian atau penilaian terhadap situasi yang membangkitkan stres. Hal ini juga dibedakan pada regulasi emosi tipe non-kognitif yaitu suppression. Tipe nonkognititf ini hanya memfokuskan pada bagaimana merubah ekspresi emosi keluar, yang memberikan efek penyesuaian secara tidak sehat karena adanya ketidaksesuaian antara pengalaman internal dan ekspresi keluarnya (Gross, 2002). Dengan demikian dapat dikatakan Cognitive reappraisal ini melibatkan semua permulaan situasi untuk mempengaruhi emosional seseorang. Dalam tingkatan stres hal ini dapat melibatkan perubahan penilaian individu terhadap suatu kejadian yang lebih berdampak positif atau kurang. Berdasarkan kajian dari Gross, diketahui bahwa ternyata penerapan strategi cognitive reappraisal lebih berdampak positif yaitu timbulnya perasaan dan emosi positif dari pada strategi regulasi expression suppression jika digunakan dalam jangka waktu yang lama.

\section{SIMPULAN}

Berdasarkan kajian teori di atas penulis dapat menyimpulkan bahwa pengajaran strategi regulasi emosi cognitive reappraisal dapat diberikan kepada pelaku cyberbullying untuk dapat mengontrol emosinya sehingga dapat mempengaruhi perilakunya dalam bentuk respon emosional yang tepat dan tidak mengarah pada tindakan agresif. Diharapkan kedepannya konselor sekolah dapat menggunakan strategi regulasi emosi cognitive reappraisal untuk membantu masalah siswa yang berkaitan dengan perilaku cyberbullying.

\section{REFERENSI}

Agatston, P. W., Kowalski, R., \& Limber, S. (2007). Students' perspectives on cyber bullying. Journal of Adolescent Health,41(6), S59-S60. doi: 10.1016/j.jadohealth.2007.09.003

Feinberg, T., \& Robey, N. (2009). Cyberbullying. The Education Digest, 74(7), 26-31. 
Garnefski, N., Kraaij, V., \& Spinhoven, P. (2001). Negative life events, cognitive emotion regulation and emotional problems. Personality and Individual Differences, 30(8), 13111327. doi: 10.1016/S0191-8869(00)00113-6

Gross, J. J. (1998). Antecedent-and response-focused emotion regulation: divergent consequences for experience, expression, and physiology. Journal of Personality and Social Psychology, 74(1), 224-237.

Gross, J. J. (2014). Emotion regulation. New York: The Guilford Press.

Gross, J. J., \& Jazaieri, H. (2014). Emotion, emotion regulation, and psychopathology: An affective science perspective. Clinical Psychological Science, 2(4), 387-401.

Gross, J. J., \& John, O. P. (2003). Individual differences in two emotion regulation processes: implications for affect, relationships, and well-being. Journal of Personality and Social Psychology, 85(2), 348-362. doi: 10.1037/0022-3514.85.2.348

Gross, J. J., \& Thompson, R. A. (2007). Emotion regulation, conceptual foundations: Handbook of emotion regulation. New York: Guilford Publications.

Hinduja, S., \& Patchin, J. W. (2012). Cyberbullying: Neither an epidemic nor a rarity. European Journal of Developmental Psychology, 9(5), 539-543.

Kiriakidis, S. P., \& Kavoura, A. (2010). Cyberbullying: A review of the literature on harassment through the internet and other electronic means. Family $\mathcal{E}$ Community Health, 33(2), 82-93.

Kowalski, R. M., Limber, S. P., Limber, S., \& Agatston, P. W. (2012). Cyberbullying: Bullying in the digital age. New Jersey: John Wiley \& Sons.

Mayer, J. D., \& Salovey, P. (1997). What is emotional intelligence? In P. Salovey \& D. Sluyter (Eds.), Emotional development and emotional intelligence. New York: Basic Books.

Mujiono. (2015). Hubungan antara kemampuan pengelolaan emosi dengan perilaku bullying siswa kelas VIII SMP Negeri 1 Kauman Tulungagung Tahun Pelajaran 2014/2015. (Unpublished master's thesis) Universitas Nusantara PGRI Kediri, Kediri, Indonesia.

Nisfiannoor, M., \& Kartika, Y. (2004). Hubungan antara regulasi emosi dan penerimaan kelompok teman sebaya pada remaja. Jurnal Psikologi, 2(2), 160-177.

Pratisti, W. D. (2013). Peran orangtua dalam perkembangan kemampuan regulasi emosi anak: Model teoritis. Surakarta: Fakultas Psikologi Universitas Muhammadiyah Surakarta.

Rasyid, M. (2012). Hubungan antara peer attachment dengan regulasi emosi remaja yang menjadi siswa di boarding school SMA Negeri 10 Samarinda. Jurnal Psikologi Pendidikan dan Perkembangan, 1(3), 1-7. 
Rice, P. F. (1999). The adolescent: Development, relationship, and culture (9th edition). Needham Heights, MA: Allyn and Bacon.

Salamah, A. (2012). Gambaran emosi dan regulasi emosi pada remaja yang memiliki saudara kandung penyandang autis. Jakarta: Fakultas Psikologi Universitas Gunadarma.

Salovey, P., \& Sluyter, D. (Eds.). (1997). Emotional development and emotional intelligence. New York: Basic Books.

Slonje, R., Smith, P. K., \& FriséN, A. (2013). The nature of cyberbullying, and strategies for prevention. Computers in Human Behavior, 29(1), 26-32. doi: 10.1016/j.chb.2012.05.024

Smith, P. K., Mahdavi, J., Carvalho, M., Fisher, S., Russell, S., \& Tippett, N. (2008). Cyberbullying: Its nature and impact in secondary school pupils. Journal of Child Psychology and Psychiatry, 49(4), 376-385.

Thompson, R. A. (1994). Emotion regulation: A theme in search of definion. Monographs of The Society for Research In Child Development, 59(2-3), 25-52. 